\title{
ESTUDIOS
}

\section{Pablo de Olavide y Jáuregui}

(Lima, 25 de enero, 1725 - Baeza, España, 24 ó 25 de febrero, 1803)

Hay un momento en la historia cultural y política de España y sus colonias de América, en que se comienza a reandar el "camino de Colón". Cierto: durante los siglos Xvi y XvIr, el hecho se produjo con menos frecuencia, aunque en muy alto nivel, que en la segunda parte del Xvirl. Era una respuesta de hecho a las visitas de "españoles europeos" (y otros europeos), a las Indias Occidentales (Ercilla, Balbuena, Ojeda, Mateo Alemán, Cetina, el conde de la Granja, etc.). Los "españoles americanos" al encontrar nuevas facilidades y alicientes para viajar a Europa, no vacilaron en dar el gran salto. Algunos regresaron a su patria; otros permanecieron en España. Entre estos últimos figura Pablo Antonio José de Olavide y Jáuregui, el limeño más universal del siglo xvu; quizás, el americano más discutido y conacido en la Europa del 790, tanto o ligeramente menos como el caraqueño Francisco de Miranda.

No se puede considerar a Olavide como un exponente genuino de los "españoles americanos" porque su amor a Francia le sacó de quicio: Defourneaux, el mejor de sus biógrafos, titula significativamente el libro pertinente: Olavide on l'afrancesado. Don Pablo lo fue; sin embargo, otro francés de vastos conocimientos en la materia, Jean Sarrailh, Rector de la Sorbona, considera al limeño a la altura de los más conspicuos españoles de su tiempo, y afirma que Olavide no tenia nada que envidiar a Jovellanos, Cabarrús, Campomanes ni Meléndez Valdés, los grandes reformistas durante el góbierno de Carlos III. De algo, sí, podemos estar seguros: Olavide no fue ni criollo ni criollista. Conviene aclarar 
el punto: por "criollos" se entendía entonces a los hijos de América con alguna porción de sangre "de Guinea", según los describe despectivamente en 1816, el joven aristócrata, también limeño, José de la Riva Aguero y Sánchez Boquete, marqués de Aulestia; ${ }^{1}$ y por criollismo se conoce el sesgo literario adherido al costumbrismo local, más folklórico que social o histórico. De ahí la denominación "español americano", diferencia no sólo del español europeo sino también del criollo. No obstante lo cual, Pablo de Olavide, pariente cercano de los condes de Vi. llanueva, era un cabalísimo mestizo: su padre fue el español Martín de Olavide; la madre, fue una criolla, doña Teresa de Jáuregui. Ambos progenitores habían constituido un hogar respetable, disponían de bienes de fortuna y gobernaban una familia corta y próspera. El hijo fue bau. tizado en la parroquia del Sagrario, contigua a la Catedral de Lima, con los nombres de Pablo Antonio José. Estudió en dos colegios jesuitas, el de San Martín y el de San Felipe (este último en la casona que hasta 1966 fue local de la Facultad de Derecho de la Universidad Mayor de San Marcos). En 1742, dando pruebas de notoria precocidad, Olavide se graduaba de abogado en la mencionada Universidad sanmarquina, y en 1745 , después de algunas gestiones, recibió nombramiento como Asesor de la Real Audiencia de Lima. ${ }^{2}$ Cumplía los 20 años. Joven, apuesto, inteligente y culto, amaba la vida, la fama y el teatro. Lo último le pudo 2carrear un desastre completo. En efecto, el 26 de octubre de 1746, ocurrió un tremendo terremoto que destruyó a casi toda la ciudad. Olavide perdió a sus padres en el sismo. Demostrando su coraje, el joven abogado logró socorrer a los condes de Villanueva, y llevó a cabo impresionantes tareas de salvataje. En premio a su valor y reconocimiento de su eficacia, le fue encomendada la tarea de colaborar como Comisario de las obras de reconstrucción de la Tres Veces Coronada Villa. Fue el comienzo de sus primeras desventuras. En el plano de reedificación, Olavide señaló como lugar más adecuado para erigir un teatro, aquel en donde existiera una iglesia destruida por el siniestro. Estaba al final de la actual segunda cuadra del Jirón Huancavelica, antigua Plazuela del Teatro, donde hoy se levanta el Teatro "Manuel Ascensio Segura", que

1 Marcelino Defourneaux, Olavide ou l'afrancesado, París, Presses Universitaires, 1959; Jean Sarrailh, L'Espagne eclairée, París, Presses Universitaires, 1954, p. 102, 103, 113, 208, 209 etc.; (Anónimo) Memoria bistórico-política sobre las causas de la Independencia de América, escrite en 1816, en el centro we la opresion, B. Aires, 1818, p. 3-Cfr. M. Menéndez y Pelayo, Historia de los beterodoxos españoles, Madrid, tomo III, Cayetano Alcázar, D. Pablo de Olan vide, Madrid, Voluntad, 1927; Estuardo Núñez, El nuevo Olavide, Lima, Biblioteca Nacional, 1970.

2 E. Núñez, El nuevo Olavide, Lima, P. Villanueva, 1970, "Apéndice: Documentales". 
fuera Teatro Municipal desde 1909 hasta 1929, y que antes se llamó Teatro Principal (1800-1909), bajo el virreinato, Teatro de la Comedia (1747-1800). Fue allí donde el Virrey Amat conoció a la pizpireta Micaela Villegas, la Perricholi. La beatería limeña y la peninsular se horrorizó con la decisión de Olavide, y tildaron de irreverente al gentil don Pablo. El Rey Fernando VI (1748-1759), sucesor del liberal Felipe V, lo mandó llamar a la Corte para que rindiera cuenta de gastos y proyectos (1748): Don Pablo tardó todo lo posible. Cumplía los 27 años cuando, en 1752, llegó a Madrid. De inmediato se le ordenó que se recluyera en la pequeña ciudad de Leganés, cercana a Madrid, donde sufrió constantes interrogatorios que acabaron exculpándolo. Allí conoció a doña Isabel de los Ríos, dos veces viuda ( $\mathrm{y}$ por tanto con experiencia en el amor), y dueña de una cuantiosa fortuna (y por consiguiente con experiencia en la vida). Don Pablo, no cumplidos los 30, y ella, pasados los 50, se unieron en matrimonio el año de 1755. Fueron dichosos. Hicieron relaciones. Una de ellas con un rico comerciante de Gijón, que les aportó nuevas amistades. De acuerdo con su esposa, Olavide abrió, en su casa, un salón o tertulia literaria. Acababa de aparecer el primer tomo de la Grande Enciclopedie Française. Concluidos los cargos con que pretendieron agobiarle sus adversarios y émulos, Olavide pasó a París, en compañía de la activa y experimentada doña Isabel. Allí se acentuaron las causas de sus futuras malandanzas. Conoció y trató al Barón d'Holbach, ejemplo de racionalismo y laicismo; al Conde de Montesquieu; al Conde de Choiseul, que aún no había firmado la orden de expulsión de los jesuitas de Francia, ni era Ministro del Rey; y, como colofón, hizo una visita a Ferney para conocer a Voltaire, quien se encontraba en el cenit de su fama. Como Ferney no estaba lejos de Ginebra, Olavide visitó la bella ciudad a fin de conocer los parajes donde ventilara Rousseau sus melancólicos sueños de "paseante solitario". De regreso a París, y en el concurrido salón de Madame de Geoffrin, conoció a Diderot, que acababa de abandonar la cárcel a donde lo sepultara una lettre de cachet de Luis XV. Al regresar a España, el apuesto limeño había congregado sobre si todas las razones justificatorias de una persecución de tipo eclesiảsticoliterario.

Olavide se consagró, entonces, con pasión a traducir y divulgar entre sus amigos de las tertulias caseras, los libros de los enciclopedistas y "filósofos", ya prohibidos por el Santo Oficio. En 1764 se arriesgó a estrenar su primera zarzuela, El celoso burlado. Hacía muy poco del fallecimiento de Ramón de la Cruz. El género costumbrista estaba de moda. Olavide compuso la obra en verso: habría sido mejor que la 
compusiera en prosa, más no lo permitían las exigencias de la moda. En cuanto a liberar el teatro del estiramiento clásico, aquella apelación a lo cotidiano constituía una buena salida. Sabemos poco sobre el éxito de la representación.

Cuando se produjo "el motín de Esquilache", El Rey, molesto, reemplazó a este su ministro, de origen italiano, con otro, español neto y de contera, muy liberal: Campomanes. Olavide estaba en su salsa; cerca del gobierno. Otro Primer Ministro, el Conde de Aranda era también liberal y amigo de Olavide. En 1767 se expedía la Real Pragmática Sanción expulsando a los jesuitas de todos los territorios de España y sus colonias. Por esos días, Olavide había sido llamado a la Corte. Mediante un procedimiento sui generis, Olavide fue designado "Síndico personero" del Rey, o sea Procurador general para lo tocante a los bienes de la Compañía de Jesús, en Andalucía, Extremadura y La Mancha. Ya había publicado La Gaceta de Madrid del 22 de junio de $1767^{\prime} \mathrm{el}$ nombramiento del limeño como Gobernador de Sevilla y Superintendente de la Colonización de Sierra Morena, en donde debía aplicarse una curiosa reforma agraria, propugnada por los ingleses Ward y Bowles, confirmada por Jovellanos (el "mayoral Jovino" de las tertulias literarias). Por estas coincidencias, Voltaire llegó a pensar que Olavide había sido inspirador de la resolución de expulsar a los jesuitas, lo que provocó su entusiasmo: un entusiasmo de terribles consecuencias para Don Pablo. Olavide estaba envanecido. No pensó llegar tan pronto a tan alto, de donde las caidas suelen doler más. En una carta a su tío Domingo de Olavide, que residía en Lima, escribe arrogantemente: "Después del Conde de Aranda y sus Ministros, soy el mayor de todos".

Había comenzado la hora de las grandes imprudencias. Para aplicar la Ley Agraria de Jovellanos, Olavide importó colonos de Baviera, Rusia, Austria, Prusia y también a compatriotas de América. Ha iniciado, acaso sin darse cuenta, una tremenda modificación de los procedimientos migratorios y contra la xenofobia ancestral de la España habsburguiana. Va más allá: solicita un cambio radical de la instrucción pública de Anda. lucía. Concretamente, acucia para llevar a cabo la inmediata reforma de $l_{a}$ Universidad de Sevilla. La Facultad de Medicina de ésta, aplaude al innovador. Apoyado, al parecer resueltamente, por el Conde de Aranda, Campomanes, Cabarrús y Meléndez Valdés, propone dar mayor ingerencia a los campesinos en las tareas de la reforma agraria. No hizo caso de la filiación religiosa de sus colonos, entre los que habían algunos protestantes. No era un buen antecedente: Tanto liberalismo resultaba 
riesgoso. Las nubes se iban cerrando en torno del limeño. Entretanto llenaba sus momentos de reposo con traducciones de piezas de teatro y representaciones de las mismas, entre ellas, obras de Racine, Voltaire, Regnard, Du Belloy, Lemièrre, Mercier. A nueve llegaban las obras dra. máticas en que Olavide intervino como autor, traductor o adaptador. ${ }^{3}$ Las ha reunido Estuardo Núñez en un volumen de suma utilidad. Aparecen 'alli, la mencionada zarzuela original de Olavide y sus principales traducciones o arreglos de comedias francesas: Fedra y Mitridates de Racine; Zaira, Alcira, Mérope y Olimpia, de Voltaire; Celmira de Durmont du Belloy; Hipermnestra, de Martín Lemièrre y El jugador, de Jean Francois Regnard. No se ha hallado el texto de su traducción de El desentor, de Mercier.

Tanto ímpetu reformista, tantos honores, tanta correspodencia peca. minosa, provocaron las iras de la Inquisición y de los conservadores: en 1773 , Olavide fue acusado por todo lo dicho, y, además, por no res. petar, en cuanto a sus obreros, el descanso dominical. Le enrostraron no ser español de nacimiento; leer libros prohibidos y, naturalmente, malversar fondos públicos. Lo último era el venablo ponzoñoso que des. truiría su reputación y alejaría cualquier apoyo extraordinario que le pudieran prestar: colocaba a Olavide a la defensiva. El Rey nombró entonces un Comisario Visitador de la obra de Sierra Morena. Olavide protestó indignado (1769). El Rey dispuso que no se insistiese contra el arrogante limeño y le confirmó en sus cargos burocráticos (1775). Al mismo tiempo, cediendo a la presión clerical, Carlos III se deshacía del Conde de Aranda como Primer Ministro; para no romper entera. mente con el que había sido su leal amigo la mandó a París como Embajador de España. Designó en su lugar a Campomanes, que ya había dejado de ser el liberal recalcitrante de 1760: no se pasan en vano por el tiempo y el poder. Olavide inmediatamente se vio envuelto en una nueva acusación: el Santo Oficio lo acusó como lector de libros prohibidos y amigo y corresponsal de los "herejes franceses". ${ }^{4}$ Eliminando po. sibilidades poco fructuosas, se había encontrado el mejor modo de invalidarlo. La imputación era cierta, aunque no secreta ni delictiva. Pero,

3 E. Núñez (comp. y prol.): Olavide. Obras dramáticas desconocidas, Lima, Bca. Nacional, 1971.

* Mendiburu, Diccionario bistórico biográfico del Perú Epoca colonial, t. VI, Lima, 1885, pp. 136-145; Cayetano Alcázar, op. cit,, passim; Modesto Lafuente, Historia General de España, Madrid, 1861-66; Llorente Historia de la Inquisición española, Madrid, 1818, tomo II, p. 549; Miguel Cabello Hurtado, Estudio critico biográfico de Pablo de Olavide, tesis para el bachillerato en Letras, Univ. de San Marcos, MS, Lima, 1944; Menéndez y Pelayo, Historia de los heterodoxos, t. III; Defourneaux, ob. cit., passim. 
perder el Apoyo del poder suele acarrear la pérdida del derecho. En el proceso salió a relucir una corrosiva carta de Voltaire en que, con su habitual sarcasmo y su imprudencia política consuetudinaria, decia:

Olavide, hombre que sabe pensar; aunque español no piensa como los bárbaros españoles; no cree en la superstición que se llama religión. Si Madrid tuviera cuatro como él, sería, sin duda, Madrid mejor que París.

El implacable mecanismo inquisitorial estaba en marcha. Olavide, al saber que se le había abierto aquella investigación secreta, se hizo presentar al propio Inquisidor General para tener una explicación personal. Vana gestión. El 26 de noviembre de 1776, la calesa verde del Santo Oficio se detenía frente a la casa de Olavide y de doña Isabel. $\mathrm{Era}_{\mathrm{a}}$ lo inevitable: comenzaba el calvario. El Santo Oficio hizo allanar y ocupar la alegre casa de Andalucía. El material libresco y epistolar no dejaba lugar a errores: el procesado pertenecía a la odiosa secta de los "enciclopedistas".

Los más encarnizados acusadores de Olavide habían sido el Superior de los Capuchinos, Fray Romualdo de Friburgo, y el agustino Eleta. Este último, como le sucediera a Peralta y Barnuevo con el P. Torrejón, fue implacable. Olavide se hallaba entre rejas, atemorizado. La caída no podía ser peor; el infeliz sólo atinaba a pensar en la fuga. Empresa difícil. Finalmente, al cabo de dos años, el 24 de noviembre de 1778, se realizó un auto diminuto (un autillo) con poca pero selecta concurrencia. El Tribunal del Santo Oficio invitó a importantes prelados y a varios seglares, entre ellos al ministro Campomanes y al famoso fabulista Samaniego. Ambos asistieron a la "función". Campomanes, implicado potencial en el proceso, guardó silencio: Olavide fue llevado al autillo con dificultades; se le veía pálido, envejecido, humillado, sin embargo ágil de mente y cauto de expresión. El cerebro mantenía su brillantez. A los 53 años de edad, el ayer elegante limeño tuvo que per. manecer cuatro largas horas de pie, mientras se leían la acusación y los testimonios. Después, lo condenaton a ocho años de reclusión, privación de todo cargo público, uso permanente de un sayal, prohibición de salir en carruaje o a caballo (podría, sí, andar a pie o en burro o mula); se le vetó de leer, salvo dos horas diarias, una de ellas dedicada a un libro de Fray Luis de Granada (durante todo el tiempo de su condena); se le confiscaron sus bienes (previendo lo cual, doña Isabel había salide a París, con buena parte de ellos, en espera de mejores días). Los de- 
litos atribuidos a Olavide eran los siguientes: amistad con Voltaire y Rousseau, críticas a la escolástica; desdén para con la Iglesia por admitir la supremacía del Estado. Al escuchar la sentencia, Olavide cayó desma. yado. Débil y enfermo lo trasladaron al Seminario de Sahagún. De vez en cuando pudo salir a pasear o a tomar baños en Cataluña, siempre con custodia. De ello se valió para, en 1780, escapar a Francia, bajo el nombre de "Manuel de Castro". Contó con la complicidad de un buen fraile cuyo nombre ignoramos.

El bagaje literario conocido de Olavide era en aquel tiempo nulo, pues no había publicado nada, aunque hubiera escrito mucho. Empero, le precedía, como insuperable heraldo, la historia de sus desventuras y de su liberalismo. Ya en Francia, en Tolosa, halló un cálido recibimiento. Lo invitaron a que siguiera viaje a París. Allí le esperaba la Academia Francesa reunida en sesión solemne para rendirle homenaje. Los oradores no pudieron ser mejores. Habló Marmontel, que se sentía ligado al Perú después de publicar su novela Les Incas (1777); D'Alambert, quien leyó unos versos encomiásticos, más oportunos que inspirados, y Diderot (antiguo amigo de Olavide), quien calificó la fiesta de "fabulosa", por el crecido número de asistentes. Don Pablo se juntó de nuevo con Isabel de los Ríos, su esposa, que, como dijimos, había salvado casi toda su fortuna y que supo a tiempo de la evasión. Doña Isabel esperaba en Paris a su marido con ternura ejemplar. Pero... El Conde de Aranda, el insigne liberal de antaño, el amigo de ayer, era ahora embajador de Carlos IV: servía, no se hacía servir. Tuvo que cumplir órdenes: presentó, pues, una denuncia formal contra Olavide reclamándolo como un reo evadido. Por otro lado, la revolución francesa se acercaba avasalla. doramente. Escarmentado con tantas desilusiones, Olavide no confiaba en la Revolución. Era ya 1782. Además, su experiencia había sido tan dura... Optó por cortar el nudo gordiano: utilizando un falso nombre, el de "Conde de Pilos", con el cual obtuvo permiso de residencia del Rey de Francia. Sin embargo, prefirió, por el momento pasar la frontera y refugiarse en Ginebra a donde volvía por segunda vez; donde podría gozar de los beneficios de la proverbial neutralidad de Helvecia; donde reviviría sus amables recuerdos de Rousseau.

Empero, atraído por el abismo, no tarda en regresar a Paris. Le toca asistir a las peores escenas del Terror. No era esa la clase de revolución con que habia soñado; ćl confiaba en la prudente élite, no en la chusma enardecida por el olor de la sangre. Vio pasar, enarboladas en las puntas de las picas fratricidas, las cabezas de algunos amigoc suyos, pálidas, do 
macradas, manchadas de negra sangre. Era el espanto. Temiendo por su propia seguridad, a pesar de los halagos de antes, y sabiendo que su amigo Miranda, cuya lealtad a la Revolución era indudable, estaba tam. bién sufriendo serios peligros y que, después de triunfar en Valmy con Doumouries, lo conducirían a la Conciergérie, Olavide decidió alejarse apresuradamente de París.

Hasta poco antes había acompañado a Miranda como codelegado de los "españoles americanos" que buscaban la Independencia. No más: abandonó el cargo y se refugió en casa de un amigo que residía en Meug-sur-le-Loire. Iba en busca de reposo. Efímera paz. El 14 de abril de 1794 (el mismo año que guillotinaron al abate Lamourette), un pelotón de la Guardia Nacional rodeó la sosegada casa campestre, Olavide fue extraído por la fuerza, y arrojado a una celda de la cárcel de Orléans. Se sospechaba de él, de su fidelidad a la Revolución: en esos días una sospecha así equivalía a la guillotina.

En la cárcel de Orléans se acentuó el proceso de arrepentimiento del limeño, arrepentimiento que los liberales llamarían apostasía. Allí escribió penosamente las largas páginas de El evangelio en triunfo. Acababa de aparecer un libro apasionado y ferviente, Delices de la religión del abate Lamourette, otra víctima de las propias ilusiones racionalistas. Se ha dicho que El evangelio en triunfo (cuyas 1,600 páginas aparecieron en Valencia, 1787), es una paráfrasis de la obra de Lamourette, salvo el cuarto tomo que contiene una dramática autobiografía del autor. Vol. veremos más adelante al caso, que no nos merece tan alegre asentimiento. Registramos aquí el subtítulo de ese libro de Olavide: Historia de un filósofo desengañado. Se trata de un libro apologético.

En conocimiento de aquel manuscrito, in to:to o en parte, el general español Luis de Urbina, pariente de Olavide, consiguió del Primer Ministro, Manuel Godoy, permiso para que Don Pablo regresara a España y que se le devolvieran sus honores y bienes.

Pese a la resistencia del Inquisidor General, que no olvidaba la interrumpida sentencia de veinte años atrás, el Rey Carlos IV y su ministro Godoy firmaron, el 14 de noviembre de 1798, un Real Decreto autorizando el regreso de Olavide a España. También disponían la res. titución de sus bienes y privilegios. No cabe duda de que el ilustre limeño había perdido la fe en sus antiguas ideas, carecia de empuje para resistir nuevas persecuciones, estaba física y moralmente vencido. Fue, pues, a vivir en una casa modesta, cerca de Baeza, lugar de sus lejanos triunfos, 
donde descansaban ya los restos de la leal Doña Isabel. Se dedicó a escribir dos libros corroboratorios de su contrición, a modo de penitencia: $E l$ Salterio español (1800), traducción y paráfrasis del libro de David, y Poemas cristianos (Madrid, Doblado, 1799), versos lánguidos y beatos. Según se advierte no tienen cabida cronológica en esta biografía, las siete novelas que, en 1828, publicaría, en Nueva York, el médico e im. presor español Lanuza.

La obra más difundida de Olavide, prácticamente la única largamente difundida es $E l$ evangelio en triunfo. Historia de un filósofo desenga. $\tilde{n} a d o$, que alcanzó, en los primeros veinte años, diez ediciones en caste. Ilano, pese a la caótica presentación de su tema y a su tremenda extensión: casi 1,600 páginas, distribuidas en cuatro apretados volúmenes. ${ }^{\bar{D}}$ La forma escogida por el autor fue la epistolar: se trata de 41 cartas en que el autor aborda toda clase de asuntos: la religión, la Revolución francesa, la irreligiosidad, la infancia en Lima, la juventud en España, episodios políticos, disquisiciones filosóficas, etc. No olvidemos que en ese tiempo, ser "filósofo" significaba ser no un especialista en sistemas filosóficos, sino un auténtico amonte de todo saber, un filo.sofo. Olavide lo era. Tiene El evangelio en triunfo cierto aire de familia con las Cantas Ameri. canas (Filadelfia, 1822) que otro peruano afrancesado, roussoniano, amante de la libertad, don Manuel Lorenzo de Vidaurre y Encalada, escribió a propósito de todo, incluso de sí mismo, en el más romántico de los desórdenes. ${ }^{6}$ Olavide, como Vidaurre, que le siguió a medio siglo de distancia, fue también, un inconsciente adelantado del romanticismo, como lo sería Lizardi en una de sus novelas Nocbes tristes y dia alegre. Por lo mismo nos suena a excesiva la importancia que se da a la influencia del abate Lamourette sobre aquella obra de Olavide.

El abate Adrien Lamourette, ${ }^{7}$ nació en Prevent (Calais) hacia 1742, o sea 17 años después que don Pablo; fue ejecutado en la guillotina, por orden de la Convención, en París, el año de 1794, tres años después de la ejecución de Luis XVI. Lamourette, un lazarista estudioso, ejerció la dirección de Saint Lazare y después fue Vicario de Atras, posición que

- A la primera edición de Valencia, 1797, siguió otra en Madrid, el mismo año, y, luego, las diez a que nos refetimos. Don Ricardo Palma coleccionó en la antigua Biblioteca Nacional de Lima alrededor de treinta ediciones de esta obra. Todo se perdió en el incendio del 10 de mayo de 1943, que dstruyó la Biblioteca Nacional de Lima. La obra fue traducida al francés.

- Cfr. Jorge G. Leguí, Vidaurre, Lima, Rosay, 1935. passim.

7 Cfr. Vicomte .... de Roquefenil, La constitution civile du clerge en: Revue des questions bistoriques, vol. XIV, cit. por: Enciclopedia Universal ilustrada, europea-ameticana. Madrid, España, Diccionario biografico unitersal, 
ocupaba al llevarse a cabo la cruenta Toma de la Bastilla (1789). Este mismo año, la Convención le designó Obispo. El abate aceptó lo que, en realidad, era un obispado laico y apóstata. Su "diócesis" cubría la zona del Ródano y el Loira, donde vivía Olavide como refugiado. Más tarde (1791), ganado o atemorizado por las circunstancias, Lamourette votó a favor de la ejecución del Rey. Un año después, 1792, el tribunal revo. lucionario de Lyon decretaba el encarcelamiento del "Obispo". Ese Tribunal Revolucionario lo condenó a muerte. Antes de subir al cadalso y bajo el influjo del célebre abate Emery, Lamourette se arrepintió públicamente de su adhesión a la causa de los Danton y Robespierre; abominó de sus actos como "convencional", y desechó como falso y nulo cuanto dijera, hiciera y escribiera contra la Iglesia: era, pues, el perfecto "filó. sofo desengañado" a que se refiere el subtítulo del libro de Olavide. Lamourette publicó varios trabajos, entre ellos, Pensées sur la Philosophie de l'incredulité, París, 1786; Delices de la Religión, París, 1787; Pensées sur la Pbilosopbie de la Foi, París, 1789; Le decret de l'Assemblee Natio. nale sur les biens du clergé, París, 1790; Proses civiques ou le Pasteur patriote, Paris, 1791.

La imputación de plagio a Lamourette por parte de Olavide, cae por su base cuando se examina el contenido autobiográfico del cuarto tomo (Ed. Madrid 1798) así como los muchos pasajes en que se mezclan asuntos religiosos, ideológicos, políticos, personales $\mathrm{y}$, a veces tan domésticos que desvirtúan la interesada sospecha.

La autenticidad de la obra de Olavide nos parece clara; dada la indole de esós escritos, pensamos también que es perfectamente entendible el propósito de desacreditar a don Pablo tanto por parte de los jacobinos como de los reaccionarios.

El General Mendiburu refiere que cuando llegó la primera edición de Evangelio en triunfo a Lima (lo que pudo suceder entre 1798 y 99 , o sea cuando estaba en auge el movimiento iluminista peruano, y acababa de pasar Humboldt por América del Sur), los pocos habitantes alfabetos y lectores de una capital virreinal, como Lima, que no llegaba a los cien mil pobladores in toto, se arrebataron los 400 ejemplares llegados. Era en cierto modo el retorno impreso del hijo pródigo. Nos dice además que la primera edición en francés data de 1805 y que la octava en castellano está fechada en 1815 (lo cual no es exacto porque esa 8a. edición es de 1803 y la 9a. es la de 1815): fortuna difícil de igualar para un autor... ya fallecido. El título de aquella edición francesa resulta pom- 
poso: Trionphe de l'Evangelie ou Mémoires d'un bomme du monde revenu des erreurs du pbilosopbisme modeme (Lyon 1805). Parece que hasta 1850 habían aparecido doce ediciones en francés. Es interesante escuchar como describe Olavide su propia peripecia:

Un destino tan triste como inevitable, me condujo a Francia, me. jor hubiera dicho, me arrastró. Yo me hallaba en París el año 1789, y ví nacer la espantosa Revolución que, en poco tiempo, ha devorado uno de los más hermosos y opulentos Reynos de la Europa. Yo fuí testigo de sus primeros trágicos sucesos, y viendo que cada día se encrespaban más las pasiones, y se anunciaban más funestas, me retiré a un lugar de corta población.

Mi designio era separarme de objetos tan terribles, y apartarme de los peligros y las contingencias; mi deseo, vivir ignorado, reparar en la amargura de mi corazón los ya pasados días de mi vida y pensar en los años eternos. Más jay! la discordia, el desorden y la angustia se apoderaron hasta de los rincones más ocultos.

A pesar de la distancia y la ausencia, mi corazón estaba continuamente destrozado. Las funestas noticias, con incesante y rápido progreso, me repetian y multiplicaban, los correos se atropellaban unos a otros y todos traían motivos de asombro y dolor.

¿No podría empezar, así, pese a la longitud de las oraciones, la "confesión de un hijo del siglo", en trance de convertir al neoclásico en protorromántico, al materialista en sentimental?

El género epistolar elegido para la obra, guarda íntima relación con el que entonces estaba en boga, sobre todo en Francia (Madame de Graffigny, Cartas de una peruana; Madame Stael; Rousseau, Montesquieu, etc.). El estilo epistolar se presta para taracear las narraciones con comentarios y citas, para introducir el dialogismo, que las acerca al teatro, del cual fue un entusiasta cultivador nuestro Olavide. Desde luego, dada su reacción contra lo que había adorado, comenzando por la Razón, es natural que derive hacia el sentimentalismo, y, por ende hacia el naciente romanticismo. Tenía que suceder.

Escuchemos otro pasaje de El Evangelio en Triunfo:

Yo ví que un día, sin orden, y por un movimiento popular que excitaron algunos impíos, el templo en que habíamos derramado 
tantas lágrimas de compunción y amor a los pies de Jesucristo, la Iglesia en que celebrábamos todos los días los terribles Misterios, fue transformado en un templo profano que llamaban de la Razón.

Para compensar y enjugar tamañas angustias, Olavide quería en. contrar un libro adecuado que, confiesa, no había podido hallar. No, no había ninguno a la altura de esos desgarramientos. Por eso, valiéndose de su propia experiencia, se creyó llamado a escribir esa obra, la que hacía falta a todo cristiano en el trance que él y muchos de su generación se vieron envueltos. Tal es el origen de El evangelio en iriunfo. Olavide fue sincero, tanto en su soberbia como en su arrepentimiento, en su piedad como en su escepticismo. De ahí que su obra pueda exhibirse como un sintoma inequívoco del "mal del siglo", precursor (y efecto) del romanticismo. De haberle sido aplicada la última pena, cuando le apresaron en la cárcel de Lyon, probablemente el nombre de Olavide "el afrancesado", según lo llama Defourneaux, sonaría como los de Chenier, Condorcet, Madame Rolland: símbolos trágicos de la crisis que rodeó a la Revolución. Olavide tuvo la mala suerte de que su vida se prolongase demasiado.

Ahora bien, el afrancesamiento con que se caracteriza a Olavide es más patente en sus novelas - si son todas auténticas- y en sus traducciones de piezas de teatro, pese a la imputación de anglófilos que se da a las primeras.

Las piezas de teatro ocuparon sus ocios entre 1764 y 1774 , que es cuando le interrumpe la carrera del Santo Oficio de la Inquisición: de ahi en adelante, no hubo tiempo para juegos retóricos: no más plays ni jeux de thèatre. La vida impuso la severidad de su mandato.

Pensamos que lo mismo debería decirse si no de todas, de la mayor parte de las novelas que se atribuyen al "autor de El Evangelia en triunfo". Bastaría recordar el tipo de actividades que embarga durante sus permanencias en Francia y Ginebra. Nos atrevemos a pensar, desde luego, que resulta inverosímil que Olavide, a través de Miranda, no entrara en relación con el gobierno británico, el cual estaba tan decidido a apo. yar la causa de la Revolución contra los españoles. Pero, si recordamos que entre 1774 y 1800 , Olavide sufre directamente el embate de la Inquisición; que enseguida es objeto de una persecución del Gobietno español por medio de su embajador en París; que entre 1789 y 1792 se 
debate entre las dudas y esperanzas provocadas por la Revolución Fran. cesa; que huye a Ginebra y regresa a Francia; que entre 1792 y 94 padece a causa de la instauración del Terror; que después escapa al sur de Francia; que enseguida es encarcelado en Lyon, y es ahí donde, de cara a su historia y a su destino, escribe el libro de su arrepentimiento, no le quedó tiempo, sino en la gozosa etapa de Leganés, Sevilla, Baeza y Madrid, para dedicarse a las bellas letras: es la época de sus novelas.

Olavide emplea para sus piezas de teatro (o las ajenas) el verso octosílabo. Lo hace con propiedad, pero sin vuelo. Revela conocimiento, no inspiración. A veces corta el sentido de una frase, para que no se interrumpa la fluidez del verso, o porque cede a una exigencia de la rima. Su zarzuela, como hemos dicho, sigue las huellas de Ramón de la Cruz.

El público español adoraba los dichos populares, los argumentos his. tóricos y folklóricos, la pintura de sitios conocidos, de hábitos consuetudinarios. Olavide brinda tal espectáculo, con menos gracia que Peralta y Barnuevo (1664-1743) en sus comedias, y sin ninguna huella de limeñismos o peruanismo, en lo que el sabio y estirado Peralta fue sorprendentemente pródigo.

La escogitación de las comedias que tradujo, se halla en relación con su inquietudes heterodoxas. ¿Podía haber olvidado la Alcira de Voltaire, en que se trata de un episodio de la conquista del Perú y se presenta un enredo de amores y venganzas (muy español, olé) entre un conquistador español y una india llamada Alcira?

Voltaire siguió en esa trama los pasos que llevarían a Marmontel a deificar a Los Incas y a su amiga, Madame de Graffigny, a tejer ese epistolario deliciosamente imposible entre dos príncipes quechuas confinados, el uno en la corte de París, y la otra en la de Madrid. Por lo demás, para un "español americano" debía de ser gratísimo compro. bar que los enciclopedistas, quizás seducidos por los idílicos relatos del Inca Garcilaso, creían en un antiguo Perú, organizado con pastoril perfección y belleza. Si la razón atraía con sus fríos imanes, el patriotismo ataba con sus cálidos lazos. Sin embargo, hay otro rasgo que, sin ser contradictorio, diferencia algo las cosas: Olavide escoge también comedias de tema y estilo neoclásico, para sus traducciones: La Mérope de Voltaire, la Celmira de Du Belloy, la Hipermnestra de Lemièrre. El gusto pòr lo racional se junta a la afición por lo pintoresco americano, 
que era una manera de rendir pleitesía al "noble et bon sauvage" exaltado en el siglo XVI por Montaigne, y convertido en pivote de una interpretación filosófica de la historia de la sociedad occidental, en el siglo xvin, por Juan Jacobo Rousseau.

Las novelas de Olavide, según Estuardo Núñez, están inspiradas en Richardson y Fielding. Es cierto que el primero es mencionado una vez por Olavide; mas no hallamos esa aseveración tan convincente como la que se refiere a los galicismos mentales y verbales que taracean el texto. En cuanto a los galicismos mentales: la forma de presentar los temas; el estilo lógico, cortado, es francés; no lo consideramos "ainglesado" como sugiere Núñez. Como eco del francesismo de la élite madrileña el antibarroquismo esencial satura cada página. Por ejemplo, en El incógnito o el fruto de la ambición, hallamos una contradicción básica e inicial, entre la nota prologal y el texto mismo de la narración. La primera nos induce a pensar en la posibilidad de que la novela hubiese sido escrita o retocada después de El evangelio en triunfo, poṛ la elogiosa mención que formula sobre el arrepentimiento; pero, desde el punto de vista del lenguaje, denota un equilibrio tan propio de un lector asiduo del francés que disfruta de tranquilidad espiritual:

El viudo Conde de Palencia quedó con un hijo único, llamado Mauricio, a quien había procurado dar la más excelente crianza. Viéndole ya de veinte años y que había acabado sus estudios, quiso que hiciese un viaje a París, para que con la vista del mundo, y el trato de las gentes, acabase de perfeccionar su educación.

Positivamente, -el relato continúa en ese tono-, una presentación así no era común de los escritores españoles ni americanos. Era de car balísimo corte francés (no inglés). Términos como "teme fiarse a su conducta" (p. 3) retratan al galiparlante, cuyo dominio de las preposiciones castellanas nunca sería perfecto. De otro lado, la frecuencia con que menciona "dolor", "lágrimas", "mansión celestial", etc. indicaría el fermento de un romántico todavía en agraz, más no mal encaminado.

Los argumentos de las novelas abren siempre una alternativa moralizante. Cada tema podría tomarse como un silogismo, como una na. rración silogistizada: dadas las premisas fluye la conclusión inequívocamente. Los pocos caracteres femeninos que presenta, están envueltos de respeto, y reflejan castidad. Aún cuando aborde un tema escabroso, lo 
reviste de honestidad. En ello pudo influir no solo su educación jesuítica, sino también su alta posición en el gobierno, su discutida condición de español de ultramar, su terca conyugalidad y la suspicaz vigilancia de la Inquisición que lo rodé prácticamente desde que llegó a Es. paña. Reiteramos, las consecuencias de su matrimonio, en 1755, a los 30 de su edad, con una dama mucho mayor que él y doblemente viuda, probablemente recelosa de cualquier expresión libertina no sólo en los labios sino en los escritos de su marido.

Como quiera que sea, don Pablo de Olavide y Jáuregui, el escabroso "Conde de Pilos" del autorizado pasaporte falso, se destaca entre los escritores coloniales del Siglo de las Luces, como el más atrayente, complejo, dinámico y fecundo. Si perteneció a la misma Logia que Miranda; si existió una delegación que compartieron ambos, como abogados de la causa de la Independencia, ante la Convención de Francia; todo eso constituye una información de menor rango: hasta su propia obra édita sería paco frente al resonante interés vital que despertó. Y aún cuando nos queda una irremediable duda acerca de la autenticidad absoluta de por lo menos algunas de sus novelas, y nos inspire inevitable descon. fianza lo prolongado de su ineditez (hasta 1828) así como su brusca irrupción editorial (todas publicadas en un mismo año), pese a eso y a cualquier otro argumento, Olavide es una de las figuras más representativas del "español americano" dentro de la órbita de la Enciclopedia; uno de los criollos (llamémoslo así, aunque el término pueda ser largamente discutido) de más enjundia y brillo de cuantos forman la constelación de artistas y sabios que motivaron la generosa admiración y el vehemente elogio del P. Feijóo, sagaz, autorizado y famoso autor del Teatro critico universal.

Olavide fue sepultado en la Iglesia Mayor de San Pablo de Baeza, el 26 de febrero de 1803. Había otorgado poder para testar el 19 del mismo mes, ante $D$. Antonio Lázaro Ortiz y Piedrole a favor de $D^{a}$ Antonia viuda de Arellano, prima del testador.

Hombre cauto, tempestad embotellada, no quiso dejar sin destino su hacienda ni la de $D^{\text {a }}$ Isabel de los Ríos. Por eso mismo, por su prolijidad en los detalles prefúnebres, sorprende no hallar mención alguna a sus novelas y comedias, aunque de estas últimas hay referencias bastantes en las informaciones sobre los años de Andalucía.

¿A qué temía si el texto era edificante? ¿Pensaba que la Inquisición le hallaría motivos de nuevas denuncias en cualquier narración o juego 
literario suyos? ¿Se miró en el espejo del Peralta anciano, acusado de hereje por haber querido testimoniar con toda el alma, lo mejor de su estilo, entusiasmo, devoción y entrega a Jesucristo?

Cualquier respuesta será imaginaria, incompleta e insatisfactoria. De todas maneras conviene seguir proguntando.

Lima, 1972

Luis AlBerto SÁNCHEZ 